Rural Sociology 78(1), 2013, pp. 51-74

DOI: $10.1111 /$ ruso. 12001

Copyright (C) 2013, by the Rural Sociological Society

\title{
Laggards or Leaders: Conservers of Traditional Agricultural Knowledge in Bolivia*
}

\author{
Jere L. Gilles \\ Department of Rural Sociology \\ University of Missouri \\ Justin L. Thomas \\ Department of Rural Sociology \\ University of Missouri \\ Corinne Valdivia \\ Department of Agricultural and Applied Economics \\ University of Missouri \\ Edwin S. Yucra \\ Departamento de Agronomía \\ Universidad Mayor de San Andrés
}

\begin{abstract}
Many sustainable agricultural practices are based on local and traditional farming knowledge. This article examines the conservation and loss of three traditional practices in the Bolivian Altiplano that agronomic research has shown increase the resiliency of small farmers in the face of climate-related risks. These practices are the use of manure, the use of local forecasts and risk-management strategies, and the preservation of crop biodiversity. Although these practices are widely used today, farmers have been steadily abandoning them during the past decade. This article examines the characteristics of those who maintain and those who abandon traditional practices to see if the abandonment of local knowledge can be explained by the adoption-diffusion literature. This research does not support the adoption-diffusion literature; although the factors related to conservation are slightly different for each practice, the findings do not support the idea that young, educated, and wealthier farmers are more likely to reject local knowledge. Instead, off-farm activities such as migration, employment, and trade seem to be related to the decline in local practices as each affects the availability of labor and the availability of people to learn these practices.
\end{abstract}

* We are grateful to the families of 11 rural communities who collaborated in the project, as well as the research team in Adapting to Change in the Andean Highlands: Practices and Strategies to Address Climate and Market Risks in Vulnerable Agroecosystems. Partial funding for this research was provided by the United States Agency for International Development and the generous support of the American People for the Sustainable Agriculture and Natural Resources Management Collaborative Research Support Program (SANREM CRSP) under terms of Cooperative Agreement No. EPP-A00-04-00013-00 to the Office of International Research and Development, Virginia Polytechnic Institute and State University, and by the McKnight Foundation under Grant Agreement 09-784. In addition, we give special thanks to Magali Garcia, Elizabeth Jimenez, Rogelio Quispe, Gladys Yana, and Cecilia Turin and members of the Andean Community of Practice for their support of this project. 


\section{Introduction}

A natural consequence of the development of new agricultural technologies has been the erosion of traditional farming and resourcemanagement knowledge. For many years this process was viewed as an unproblematic aspect of progress, but as concerns over the sustainability of a petroleum-based agriculture have grown, this is no longer the case. Interest in traditional agricultural knowledge has increased because traditional agricultural systems appear to be more sustainable than "conventional" ones (Altieri 2004). Many practices identified with modern sustainable agriculture are in fact adaptations of traditional practices. Some examples of these adaptations are organic agriculture, crop rotations, grass-fed livestock, local food systems, and heirloom crop varieties.

In order to preserve this potentially valuable knowledge, it is important to understand who maintains traditional practices, and why. This article seeks to address the first of these two questions, to understand the characteristics of those who maintain traditional agricultural and resource-management practices in the face of rapid technological change.

Three practices from the Bolivian Altiplano are the focus of this study - the use of bioindicators to forecast weather, the cultivation of multiple varieties of potatoes (the staple crop in this region), and the use of manure. Each of these practices is either more sustainable than modern agricultural practices or has the potential to reduce the impact of climate change.

The literature on this topic is not as abundant as one would expect, based on the importance given to the topic. Focus in recent years has been more on techniques for discovering and conserving traditional knowledge than on understanding those who maintain traditional practices when their neighbors are abandoning them. However, the literatures on the diffusion of innovations, indigenous knowledge, and participatory research, as well as case studies of specific practices, are relevant to this question.

\section{Diffusion of Innovations and Conservation of Traditional Knowledge}

Rural sociological research on agricultural practices was dominated by the diffusion-of-innovation approach until the late 1970s (Constance 2009). The literature on diffusion of innovations has explicitly focused on those who abandon traditional practices rather than those who maintain them, but implicitly it has shaped many ideas about who maintains traditional practices. This work began with the study of hybrid corn in the Midwest in the 1940s and continues today (Griliches 1957; Rogers 
2003; Ryan and Gross 1943). Hybrid maize greatly increased per acre yields and its success led to the elimination of local landrace varieties of corn and transformed the seed system from a self-sustaining, farmerbased regime to one based on purchasing off-farm seed stocks from seed companies and depending on chemical fertilizers in order to obtain maximum yields (Schlebecker 1977). The success of hybrid corn provided the inspiration for the research that led to the Green Revolution, with a similar impact on local farming systems.

Since the 1940 s, academic journals have published more than 4,000 diffusion studies (Wejnert 2002). This literature has looked at the influence of the characteristics of context of innovation, the characteristics of innovations, and adopter characteristics on adoption. The last two factors are most important for this research-character of adopters and to a lesser extent the characteristics of innovations. The study of innovator characteristics is particularly relevant because it distinguishes the characteristics of innovators from those who are among the last to adopt, the so-called "laggards."

Diffusion researchers have paid little attention to those who maintain traditional practices. Adoption-diffusion theory assumes that innovations are financially superior (Saltiel, Bauder, and Palakovich 1994). Consequently, those who do not adopt will, for all practical purposes, disappear (the famous "S" curve). For that reason the focus has been on factors that slow or facilitate the adoption process. The diffusion literature views adoption and nonadoption as mutually exclusive categories. The idea that a person could adopt innovations and maintain traditional practices is not considered.

The diffusion literature indicates that later adopters of innovations ("laggards") are older, are less educated, have less media exposure, and have more traditional values than other farmers. In addition, they tend to live in more isolated and more traditional communities. Research on the characteristics of farmers who change from modern conventional farming to more sustainable practices has been less conclusive than studies of the adoption of modern practices. For example, in the case of conservation practices, the relationship between age and adoption is related to the type of conservation practice and context (Knowler and Bradshaw 2007).

Three characteristics of innovations that influence the adoption rate are trialability, ease of observing benefits, and compatibility with existing systems. Innovations where it is easy to observe benefits, such as yields from fertilizers or new varieties, are more quickly adopted. On the other hand, innovations whose effects are less easily observable, such as soilconservation practices and integrated pest management, are adopted 
more slowly. Likewise, innovations like new seed varieties are more quickly adopted because they can be more easily and seamlessly integrated into existing production systems than practices like conservation agriculture that require reorganization of production systems.

Since the focus of diffusion research is on the replacement of traditional practices, our initial hypothesis will be that the conservers of traditional agricultural practices share the characteristics of late adopters.

The critiques of research in diffusion of innovation focus largely on the consequences of the application of diffusion research rather than on the theory itself. Use of this approach to increase adoption rates often favored large farmers over small ones and favored regions with better natural resource endowments. This led to increased inequality in rural areas (Grabowski 1979; Hayami 1981). For example, early Green Revolution technology was designed for irrigated crops and areas endowed with good soils and rainfall. Producers in marginal and rain-fed areas were often disadvantaged as commodity prices fell because of surpluses created by the Green Revolution varieties-especially in areas with poor marketing infrastructures (Hayami 1981).

New technologies also required farmers to have increased access to credit and information in order to purchase and use improved seed, fertilizer, and irrigation equipment, which discriminated against the poor. In most countries this meant that only larger farmers could fully take advantage of these technologies. Other critics emphasized the negative impact of the adoption of Green Revolution technologies on sustainability and crop biodiversity (Altieri 1999, 2004). These critiques did not challenge the characterization of early and late adopters, but instead pointed out the inequities, biases, and undesirable consequences of strategies based on the theory that favored the well-off over poorer farmers (Hayami 1981).

\section{Indigenous Knowledge and Conservation of Traditional Practices}

The literature on indigenous knowledge in development also addresses the issue of the conservation of traditional practices in a different way than the literature on diffusion of innovations. While the diffusion approach sees the disappearance of traditional practices as a natural consequence of modernization, the indigenous knowledge approach looks for the potential value of these practices. Although indigenous knowledge has long been of interest to applied anthropologists (Warren 1991), this subject entered the development mainstream as a result of the popularity of participatory approaches to rural development (Sillitoe 
1998; Sillitoe and Marzano 2009). The failures of the top-down approach of diffusion-based agricultural development led to the "Farmer First" movement and to the valorization of the practical knowledge of farmers, which included indigenous knowledge (Chambers, Pacey, and Thrupp 1989). Farmers, supporters of this movement said, were not mere passive recipients of scientific knowledge but had valuable and useful knowledge themselves. As a result, in recent years more participatory approaches to research and extension have been promoted as being more efficient and equitable (Gurung and Menter 2004; Hayward, Simpson, and Wood 2004). These approaches were more adapted to the actual conditions faced by poorer farmers and reduced the large-farmer bias inherent in approaches based on the diffusion-of-innovations paradigm. As a result of the participatory approach, scholars now see technological change in agriculture as a search for jointly negotiated advances instead of a top-down approach (Sillitoe 1998:225).

While participatory approaches to agricultural development made clear the potential contribution of traditional knowledge and practices, they did not question the assumptions of the literature on diffusion of innovation concerning the characteristics of those farmers who maintain traditional practices. Instead, the focus was on the negative impact and the fact that Western development professionals and scientists promoted inappropriate technologies by not valuing local knowledge. The emphasis was on studying and valuing rather than understanding who conserved practices in the face of modern alternatives and why. This emphasis changed with the Rio de Janeiro conference in 1992, which resulted in the Convention of Bio-diversity, implemented at the end of 1993. The convention generated interest in conserving the genetic diversity of food sources and led to investment in research on in situ preservation of traditional varieties of major food crops (Altieri 1999; Bellón 2004; Brush 2004; Brush, Taylor, and Bellón 1992; Valdivia, Dunn, and Jetté 1996). This research indicates that farmers who cultivate multiple varieties and maintain crop biodiversity tend to be older, have smaller farms, and have less connection to markets. The research negatively associates migration, market integration, and off-farm employment with maintenance of biodiversity. The connection between farm size and wealth has been disputed, however, because there are some cases where larger farmers are more likely to have more diversified production systems and preserve biodiversity (Brush 2004; Valdivia 2004).

While there has been considerable research on the preservation of genetic diversity and local knowledge about the beneficial quality of local plant varieties, there has been much less work on the conservation of other traditional practices. Zimmerer's (1993) research on the 
conservation of traditional soil- and water-conservation practices in the Andes is an example of such work. He found that a family's available labor supply had a strong association with the maintenance of traditional soil management practices. Households that had more available labor and who did not use temporary migration as a livelihood strategy were more likely to utilize traditional soil-management practices. He also found that the more a family depended on sales to the market for its overall well-being, the less likely it was to use traditional soilmanagement practices. Interestingly, these findings are echoed in Giller et al.'s (2009) review of the adoption of conservation agriculture in Africa.

This research is distinguished from previous work on this topic because in the Bolivian Altiplano we are not dealing with practices that have been forgotten by most farmers and need to be recovered (Nazarea 2005). Many farmers still use these practices, and most of those who do not are familiar with them. In this case it is not necessary to recover past practices, but to reverse the decline in their use (Coppock and Valdivia 2001; Materer 2001).

\section{Practices Studied}

This study examines the characteristics of farmers who have conserved the use of three agricultural practices, which not only may be sustainable practices but also will help reduce some of the impact of climate change and climate variability. Each of these practices can contribute to the sustainability and resilience of local farming systems. The first is the use of organic fertilizer (manure), the second is the use of bioindicators to make forecasts to manage weather-related risk, and the third is the cultivation of multiple varieties of potatoes (the staple food crop) within a farm. Use of these practices has declined in recent decades. In the case of manure, the decline has been slow, and a majority of farmers still use it, sometimes in combination with chemical fertilizers. Farmers in the Altiplano still plant more than one variety of potato, but the number of varieties grown has declined over time. Survey data for part of Umala from 2001 indicates that the decline in the use of bioindicators has occurred in less than a decade, but still more than a third of the farmers use them (Gilles and Valdivia 2009).

Researchers have long seen the use of manure and other organic amendments as a more sustainable practice than a dependence on petroleum-based fertilizers. However, in addition to manure's contribution as a fertilizer it increases the resiliency of farming systems to extreme weather events. The use of manure increases the water- 
retention capacity of soils and buffers temperature changes (Fernandes et al. 1997). As a result, the use of manure reduces damage to crops due to prolonged dry spells and reduces the severity of frosts-events that we will see below are going to be more frequent according to climate change models for our study area.

Andean farmers have used observations of natural phenomena such as stars, winds, plants, and animals as part of their strategies to deal with weather-related risk. These observations help farmers decide when to plant, where to plant, what to plant, and whether production will be good or bad. Bioindicators are the plants and animals that farmers observe to make these decisions. Previous research by Orlove, Chiang, and Cane $(2000,2002)$ has validated the predictive value of astronomical observations for predicting wet and dry years and for predicting potato production. There is interest in validating other indicators. If successfully used, these techniques can lead to planting under the best soil and environmental conditions and reduce losses due to frosts and extreme weather events.

The planting of multiple varieties of potatoes in the same farm is an age-old risk management strategy in the Andes; as a consequence, researchers have identified more than 750 varieties of potatoes in Bolivia alone (Hawkes and Hjerting 1989). Farmers plant potatoes with different maturation dates, different uses, different market niches, and different levels of frost resistance to reduce losses to severe weather and to price volatility (Materer 2001; Valdivia et al. 2003). Planting multiple varieties of potatoes in the same field can also reduce pest and disease damage (Garrett 2000). Over the past 20 years, however, there has been a trend to more monoculture.

\section{Research Setting}

We conducted the research described in this article in the Bolivian Altiplano. The Altiplano is an inland basin lying between the Eastern and Western Cordillera of the Andes that includes parts of Peru, Bolivia, Chile, and Argentina. Elevation levels vary from 13,900 feet (4,200 meters $)$ to 11,100 feet (3,400 meters) with an average elevation of 12,200 feet (3,700 meters). Rainfall levels in the Altiplano vary from 800 millimeters in the north near Lake Titicaca to 200 millimeters in the south. The northern Altiplano receives about 600 millimeters of precipitation annually, the central Altiplano around 400 millimeters. Low rainfall and high evapotranspiration rates make the region particularly susceptible to drought. Even in "normal" years (50 percent dependable precipitation), there is a large probability that crops will suffer from dry spells (García 


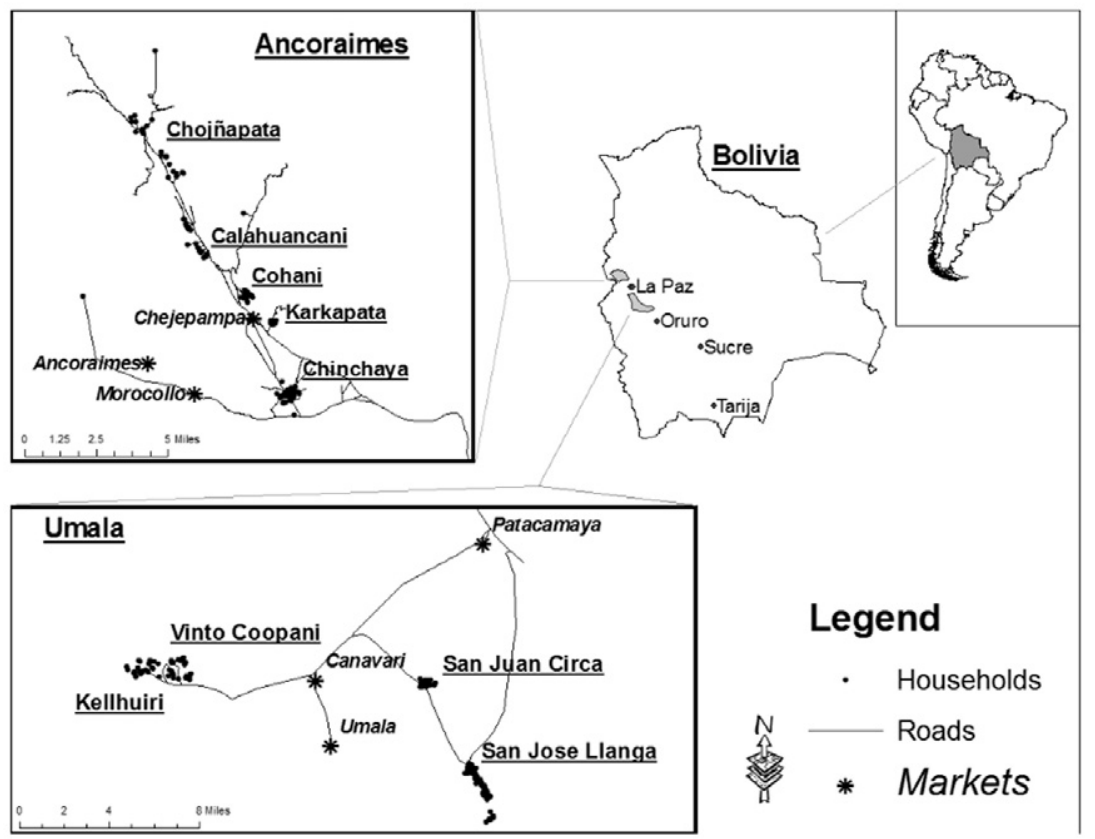

Figure 1. Map of Study Location Including Study Communities.

et al. 2007). The region's high altitude produces cold temperaturessummer highs rarely pass the low to mid 70s Fahrenheit and winter low temperatures may approach 0 degrees. As a result, there is a high risk of frosts and hail even in the warmest months of the year. Aymara farmers and herders are the dominant population of the region. The impact of global climate change is greater at high elevations in the tropics, and the Altiplano is experiencing warming trends, higher evapotranspiration, later onset of rains, and an increase in extreme weather events. All of these are likely to lead to an increased frequency of dry spells, floods, killing frosts, and hailstorms (Seth et al. 2010).

We conducted this study in two municipios (similar to U.S. counties) in the Bolivian Altiplano, Ancoraimes in the northern Altiplano and Umala in the central Altiplano (see Figure 1). While both municipios are located between 12,500 and 13,900 feet (3,800 and 4,200 meters) above sea level, Ancoraimes is located nearer to Lake Titicaca than Umala. Thus, Ancoraimes receives more annual rainfall, 21-25 inches (530-638 millimeters) compared to 14-18 inches (354-463 millimeters) in Umala. In addition to the difference in precipitation, the rate of evapotranspiration is higher in Umala, which reduces further the water 
Table 1. Description of Variables in the Regression Analysis.

\begin{tabular}{|c|c|}
\hline Variable & Description \\
\hline Municipio & Indicator for municipality ( $1=$ Ancoraimes, $0=$ Umala $)$. \\
\hline Age & Age of the head of the household. \\
\hline Education & $\begin{array}{l}\text { Level of education of head of household }(0=\text { no primary, } \\
1=\text { primary, } 2=\text { secondary, } 3=\text { postsecondary })\end{array}$ \\
\hline Labor & $\begin{array}{l}\text { Total labor units living in household (if age is less than } 3 \text { years, } \\
\text { available labor }=0 \text {; if age is } 4-5 \text {, available labor }=.1 \text {; if age is } 6-8 \text {, } \\
\text { available labor }=.3 \text {; if age is } 9-12 \text {, available labor }=.5 \text {; if age is } \\
13-17 \text {, available labor }=.8 \text {; if age is } 18-59 \text {, available labor }=1 \text {; if } \\
\text { age is } 60-65 \text {, available labor }=.8 \text {; if age is } 66 \text { or greater, available } \\
\text { labor }=.3) \text {. }\end{array}$ \\
\hline Farm size & Size of household farm in hectares. \\
\hline Total income & $\begin{array}{l}\text { Total household income, including in-kind. (The current exchange } \\
\text { is approximately } 7 \text { Bolivianos to } \$ 1 \text { U.S. Variable is measured in } \\
1,000 \text { Bolivianos for regression analyses.) }\end{array}$ \\
\hline Time to market & $\begin{array}{l}\text { Hours of travel for household to market where primary } \\
\text { income-earning product is sold. }\end{array}$ \\
\hline Gender & Indicator for male head of household $(0=$ no, $1=$ yes $)$ \\
\hline Off-farm work & Indicator for head of household engaging in off-farm work. \\
\hline Tractor & Indicator for use of tractor in potato production. \\
\hline Irrigation & Indicator for use of irrigation in potato production. \\
\hline Fertilizer & Indicator for use of chemical fertilizer in potato production. \\
\hline Total sheep & Total number of sheep on farm. \\
\hline Total cattle & Total number of cattle on farm. \\
\hline Manure & Indicator for use of manure in potato production. \\
\hline Bioindicator & Indicator for use of biological indicators by household. \\
\hline Potato variety & Count of varieties of potatoes cultivated by household. \\
\hline
\end{tabular}

available for crops (Thibeault, Seth, and Wang 2010). Umala is also more susceptible to frosts than Ancoraimes.

The landscape of Ancoraimes also consists of steeper slopes and smaller farms than those found in Umala (see Table 1 for farm size comparison). While Figure 1 shows how both municipios appear to be a similar distance from the Bolivian capital of $\mathrm{La} \mathrm{Paz}$, only the residents of Ancoraimes market their products there. Umala farmers market their products in a large nearby community. In both areas potatoes are the principal crop, but in Ancoraimes onions and peas are important cash crops while dairy farming is an important commercial activity in Umala.

Families in Ancoraimes tend to be poorer, have fewer livestock, and own less land, and they are more likely to be headed by women. Except for irrigation, farmers in Ancoraimes are less likely to use modern technologies like tractors and chemical fertilizers, but due to poverty and land shortages they are also less likely to maintain many traditional practices such as crop rotation. The region is in the process of rapid technological change due to increased integration in national and 
international markets. Although improved agricultural practices were introduced in the 1960s and 1970s, significant change in production systems began in the early 1990s with the introduction of improved varieties adapted to the region. Production systems that were as recently as a decade ago dedicated to meeting household subsistence needs are now market oriented. For example, quinoa-an Andean grain formerly used only for household consumption-now is a highly valued commercial crop because of increased popularity in North America and Europe (Bennett and Balvanera 2007).

The changes noted above have affected the three traditional practices that are the focus of this study. While each of these practices contributes to the sustainability of agricultural production systems and reduces losses due to climate variability, each practice is disappearing. Currently 55 percent of the farmers in Umala and 37 percent in Ancoraimes are using chemical fertilizers and more might if they had the resources to obtain it. The use of bioindicators is declining even more rapidly. In Ancoraimes less than 10 percent of the population uses bioindicators, and in Umala the rate of use has fallen from near 100 percent a decade ago to less than 40 percent in 2006 (Gilles and Valdivia 2009). The number of potato varieties planted on individual farms has also declined, thanks in part to the commercial success of a variety known as "Waycha," which is currently planted on nearly 90 percent of the farms in our sample. Unlike many traditional varieties that have a single use, Waycha is suitable for multiple uses. In addition it fetches a premium price in urban markets, responds well to chemical fertilizers, is more resistant to pests than some traditional varieties, and requires less labor to harvest (Aguirre et al. 1999).

Given the rapid change that farming systems are undergoing today and the increased interest in the conservation of indigenous knowledge, the Altiplano may be an ideal place to study the process of abandoning or conserving traditional practices. In our case we will examine the characteristics of farmers who conserve traditional practices.

\section{Research Methods and Analysis}

Data used in this analysis come from a household survey of livelihoods and production practices conducted in August and September 2006 in the municipios of Ancoraimes and Umala. We included 330 households in the study, 149 from Ancoraimes and 181 from Umala, comprising 11 rural communities. The survey provided baseline data to measure the impact of a research project that included the evaluation of traditional practices. We contacted community officials in the two regions and 
invited them to participate in the research project. Those who agreed provided a census of households forming the community, which we used to select participants at random for the survey. Two teams of three trained bilingual interviewers (Spanish and Aymara) in each region lived in the rural communities for two months while conducting interviews. We monitored the teams of interviewers and reviewed the completed questionnaires with agronomists and social scientists, in case we needed follow-up clarifications. The teams interviewed heads of household, men and women, in Spanish and Aymara. Each interview lasted on average 60 minutes. Participatory workshops played an important role in the design and analysis of the questionnaire. We held workshops in each community to identify the characteristics of production systems and trends related to climate, technology use, cultural change, demographic change, and economic change. We incorporated this information into the design of the survey. We also shared the results of the survey in community workshops to obtain local views of results.

To analyze the characteristics of farmers using traditional practices, we developed three models: Use of bioindicators in farming decisions, use of manure as a fertilizer in crops, and planting multiple varieties of potatoes. The first two are binary dependent variables, use or nonuse of bioindicators in farming decisions and use or nonuse of manure as fertilizer in potato farming. The third is a continuous variable that counts the number of potato varieties planted in a given year. (See Table 1.) The independent or explanatory variables used in the analysis are organized into two groups: (1) household characteristics and context and (2) technology use. The household characteristics include the human, natural, and economic capital, as well as the income generated from activities on and off the farm. This category included the age, sex, education, the labor available to the household, size of farm, income sources of the head of household, household income, and household wealth measured by livestock (a savings practice due to the lack of banking). Context variables include a variable representing the region and a variable measuring distance to market (Table 1). The technology variables include modern and traditional technologies, three modern (use of tractor, use of chemical fertilizer, and use of irrigation [usually with low-lift motor pumps]) and two of three traditional technologies (manure use, bioindicators, and potato varieties). Irrigation, although a traditional technology in the inter-Andean valleys, is not one in the study region. In addition, the predominant form of irrigation is using low-lift pumps rather than gravity-flow systems.

Table 2 summarizes the means and distributions of these variables for each municipio. While there are no differences in the mean age of 
Table 2. Municipio Means and Means Tests by Municipio and by Community for Variables in Regression Analysis.

\begin{tabular}{|c|c|c|c|c|}
\hline & Umala & Ancoraimes & & \\
\hline & $N=181$ & $N=149$ & & \\
\hline \multicolumn{5}{|c|}{ Mean values of continuous and categorical variables } \\
\hline & & & Sig. (2-tailed) & Sig. $(F)$ \\
\hline Age & 49.8 & 47.6 & .191 & .339 \\
\hline Education & 1.3 & 1.1 & .030 & .195 \\
\hline Labor & 2.7 & 2.8 & .552 & .012 \\
\hline Farm size & 8.8 & 1.5 & .000 & .000 \\
\hline Total income ${ }^{\mathrm{a}}$ & 20,517 & 6,823 & .000 & .000 \\
\hline Time to market & 1.0 & 2.3 & .000 & .000 \\
\hline Total sheep & 24.7 & 18.1 & .010 & .001 \\
\hline Total cattle & 5.3 & 2.7 & .000 & .000 \\
\hline Potato diversity & 3.8 & 2.1 & .000 & .011 \\
\hline \multicolumn{5}{|c|}{ Percentage of positive responses to categorical variables } \\
\hline & & & Pearson $X^{2}$ & Sig. (2-sided) \\
\hline$\overline{\text { Gender }}$ & $81 \%$ & $77 \%$ & .599 & .439 \\
\hline Off-farm work & $38 \%$ & $36 \%$ & .228 & .633 \\
\hline Tractor & $73 \%$ & $37 \%$ & 43.170 & .000 \\
\hline Irrigation & $8 \%$ & $26 \%$ & 19.106 & .000 \\
\hline Fertilizer & $55 \%$ & $37 \%$ & 10.384 & .001 \\
\hline Manure & $43 \%$ & $97 \%$ & 108.144 & .000 \\
\hline Bioindicator & $37 \%$ & $4 \%$ & 50.410 & .000 \\
\hline
\end{tabular}

${ }^{\mathrm{a}}$ In Bolivianos.

household heads, available labor, and education, Umala has significantly larger farm size, income, number of livestock, and number of potato varieties, and takes significantly less time to market potato varieties. There are no significant differences in the percentage of households with male heads of household and members working off-farm. Umala has significantly more tractor use, more fertilizer use, and more people using bioindicators, while Ancoraimes has more people who use manure and irrigation.

\section{Binary Logistic and Ordinary Least Squares Regression}

We studied three traditional practices: (1) whether a household used manure as a fertilizer, (2) whether farmers used bioindicators in their decision making, and (3) the number of potato varieties a farmer cultivated. This study uses two types of regressions because of the nature of the dependent variable. In the case of the number of potato varieties planted, a count variable between 0 and 10 normally distributed, we used 
an ordinary least squares (OLS) regression (Long 1997). For the use of manure and the use of bioindicators we used a binary logistic regression since the dependent variable is discrete (yes or no responses). The binary logistic regression provides several benefits when dealing with discrete outcomes (Tabachnick and Findell 2007). For example, in the logistic regression model "predictors can be any mix of continuous, discrete and dichotomous variables ... [and this regression] is especially useful when the distribution of responses on the DV [dependent variable] is expected to be nonlinear with one or more of the IVs [independent variables]" (Tabachnick and Findell 2007:437).

We estimated two models for each traditional practice. Model 1 includes variables that capture household and context characteristics in the use of traditional agricultural practice. More specifically, variables include education of the head of household, age of head of household, farm size, farm size squared, male household head, off-farm income, number of sheep, and number of cattle. Because the distributions of the farm size and income variables were not normal, we also included these variables squared. Distance to the market and municipio were the variables used to capture the effect of context (see Table 2). Model 2 adds modern and traditional technology variables.

We included income, education, age, and wealth because these are important variables used in the diffusion-of-innovation literature (Rogers 2003; Shively 1997). Gender has been associated with preservation of indigenous crop varieties, and off-farm employment has been associated with abandonment of soil-conservation practices such as the use of manure.

Model 2 includes the use of modern technologies and traditional practices to determine if there is a relationship between the use of traditional practices and the use of modern technologies (Griliches 1960). The variables for modern practices include whether the tractor is used in potato production, use of irrigation, and whether chemical fertilizer is used. The traditional practices included as independent variables are other than the dependent variable.

Three observations (households) were outliers excluded from the binary logistic regression analyses because excluding them significantly improved the model fit with only minimal effect on results. In the OLS estimation the removal of outliers did not improve the results, therefore we included all 330 households in the analysis. We compared the models using goodness-of-fit measures, chi-square statistics, Cox and Snell $R$-square, and Nagelkerke $R$-square. We included ending log-likelihood values to compare Model 1 and Model 2 for each logistic regression, and to see if the added variables increase the goodness of fit. 
Table 3. Binary Logistic Regression Analysis.

\begin{tabular}{|c|c|c|c|c|}
\hline & \multicolumn{2}{|c|}{ Manure } & \multicolumn{2}{|c|}{ Bioindicator } \\
\hline & Model 1 & Model 2 & Model 1 & Model 2 \\
\hline Municipio & $4.712 * * *$ & $6.519 * * *$ & $-4.037 * * *$ & $-3.825 * * *$ \\
\hline Age & -.013 & -.015 & .019 & .022 \\
\hline \multicolumn{5}{|l|}{ Education } \\
\hline Education (1) & .547 & 1.525 & $-1.522 *$ & $-1.637^{*}$ \\
\hline Education (2) & .262 & 1.678 & -1.611 & $-1.952 *$ \\
\hline Education (3) & -1.473 & -1.606 & -1.435 & -1.345 \\
\hline Labor & .236 & .181 & $.321 *$ & $.294^{*}$ \\
\hline Farm size & -.133 & .036 & .025 & -.012 \\
\hline Farm size squared & .006 & .001 & -.003 & -.002 \\
\hline Total income & $-.109 * *$ & -.077 & .052 & .054 \\
\hline Total income squared & $.001 *$ & .000 & .000 & -.001 \\
\hline Time to market & -.461 & -.003 & .199 & .022 \\
\hline Gender & .806 & 1.097 & .205 & .182 \\
\hline Total sheep & $.029 * *$ & .021 & .002 & .000 \\
\hline Total cattle & $-.231 * *$ & $-.222 *$ & .011 & .036 \\
\hline Off-farm work & .484 & .572 & -.187 & -.249 \\
\hline Tractor & & $-4.339 * *$ & & .977 \\
\hline Irrigation & & $1.548^{*}$ & & -.435 \\
\hline Fertilizer & & $-.973 * *$ & & .016 \\
\hline Manure & & & & $1.129 *$ \\
\hline Bioindicator & & .856 & & \\
\hline Potato diversity & & $.666 * *$ & & $.298 *$ \\
\hline Constant & 1.413 & .114 & -2.020 & $-3.946 * *$ \\
\hline-2 Log likelihood & 200.680 & 131.028 & 233.676 & 221.278 \\
\hline
\end{tabular}

$* p<.05, * * p<.01, * * * p<.001$.

Cox and Snell $R$-square for manure: Model 1.476 , Model 2.577 ; for bioindicator: Model 1.265 , Model 2.292 .

Nagelkerke $R$-square for manure: Model 1.664 , Model 2.805 ; for bioindicator: Model 1 .413 , Model 2.456 .

\section{Results}

Although the results we obtained varied by practice, they did not support the idea that those who maintained traditional practices have the characteristics of the "laggards" described in the diffusion-of-innovations approach. Table 3 presents the results of the analysis for the use of manure and bioindicators.

\section{Use of Manure}

Model 1 of manure use includes only household characteristics and context. Model 2 includes the effect of technologies, modern and traditional. Overall pseudo $R$-squares were high and improved with the technology model, and the goodness of fit improved as the -2 Log likehood 
fell between Models 1 and 2. Income is significantly related to the use of manure, but not in the way expected from the diffusion-of-innovations theory. The coefficients indicate that the poorest and very rich farmers are more likely to use manure. While we would expect low-income farmers to use resources readily available on the farm, rich farmers often use manure in combination with chemical fertilizers. Families in Ancoraimes were also more than 100 times more likely than farmers in Umala to use manure. Sheep numbers, as expected, were positively related to manure use, as manure from these animals is the main and preferred source of manure in the region (participatory assessments in the regions demostrated this). Cattle numbers were negatively related to use of manure. Farmers with cattle were less likely to use manure in farming. More often farm households use this type of manure for fuel.

Model 2 adds modern technologies and traditional practices. The predictive value of socioeconomic indicators disappeared, with the exception of number of cattle, which remains negative $(p<.05)$. The likelihood of farmers in Ancoraimes using manure increased; they were 700 times more likely. Producers who used tractors and those who used chemical fertilizers were less likely to use manure, while farmers who irrigated and those who planted more varieties of potatoes were more likely to use it. The tractor is a technology introduced in the 1960s, but it became widely used in the 1990s (Markowitz and Valdivia 2001) as a labor-saving technology that facilitated planting of larger plots in less time; it has reduced use of manure. It should be noted that use of chemical fertilizer was not significant, while those who maintain multiple varieties of potatoes are more likely to use manure (Table 3).

\section{Use of Bioindicators}

Model 1 (Table 3 ) was statistically significant $(p<.000)$. Pseudo $R$-square (Nagelkerke) is 0.413 . Results indicate that farmers in Ancoraimes are less likely to use the bioindicators. Having primary education reduced the likelihood of using bioindicators, and available labor increased the likelihood of using bioindicators, at 5 percent. Other variables were not significant.

Model 2, measuring the effect of including traditional and new technologies, improves the goodness-of-fit measures of the model. Both primary and secondary education become significant, and negative, meaning that those farmers with primary and secondary education were less likely to use bioindicators. Available labor continued to be significant and positive at a 5 percent level, in the use of bioindicators to manage weather-related risks in farming. While the new technologies do 
Table 4. OLS Regression Analysis.

\begin{tabular}{lcc}
\hline & \multicolumn{2}{c}{ Potato Variety } \\
\cline { 2 - 3 } & Model 1 & Model 2 \\
\hline Municipio & $-1.584^{* * *}$ & $-1.643^{* * *}$ \\
Age & .002 & .002 \\
Education & .094 & .165 \\
Labor & .031 & -.027 \\
Farm size & .053 & -.025 \\
Farm size squared & .001 & .001 \\
Total income & $.034^{*}$ & $.046^{* *}$ \\
Total income squared & .000 & .000 \\
Time to market & .058 & .082 \\
Gender & .009 & -.082 \\
Total sheep & $.010^{* *}$ & $.006^{*}$ \\
Total cattle & .001 & .034 \\
Off farm work & .128 & .127 \\
Tractor & & $-.413^{*}$ \\
Irrigation & & .144 \\
Fertilizer & & .041 \\
Manure & & $.567^{* *}$ \\
Bioindicator & $2.840^{* * *}$ & $.476^{* *}$ \\
Constant & $.373(.347)$ & $2.380^{* * *}$ \\
$R$-square (adjusted) & & $.425(.392)$ \\
\hline$* p<.05, * * p<.01, * * * p<.001$. &
\end{tabular}

not have an effect on using bioindicators, the traditional practices of manure use and potato varieties do increase the likelihood of using the indicators, by three times and more than one, respectively (Table 3).

\section{Planting Multiple Varieties of Potatoes}

We analyzed the models to measure the effect of socioeconomic characteristics and context (Model 1) and the effect of traditional and modern technologies (Model 2) in planting a diversity of potato varietes using OLS. $F$ tests for both models were statistically signficant $(p<.000)$. $R$-square increased with Model 2. The three technologies and practices added were significant at $p<.01$. Factors related to planting multiple potato varieties (Table 4) show that farmers who live in Umala, those who have higher incomes, and those who have more sheep plant more potato varieties. The $R$-square value is .373 .

Model 2 is statistically signficant $(F=12.771 ; p<.000)$. The relationships continue to exist when the technology variables are included, though the significance levels change for sheep and income. Higher income $(p<.01)$ has a positive effect on planting a diversity of potatoes, 
and so does having sheep $(p<.05)$. Use of a tractor has a negative effect $(p<.05)$ on the number of varieties planted, while those farmers who use bioindicators to inform their farming decisions $(p<.01)$ plant many potato varieties. Manure has a positive and significant effect on the number of potato varieties planted. Those using tractors tend to plant fewer varieties, while those who use manure and bioindicators tend to cultivate more varieties.

\section{Discussion}

Disappearance of traditional agricultural practices is not generally associated with the variables linked to the adoption of modern farming technologies such as age, education, and wealth. Disappearance seems to be related to a complex set of factors related to changes in systems of production and in livelihood strategies influenced by labor and commodity markets-making it more difficult or less attractive to maintain traditional strategies. For example, many farmers have less ability to negotiate market prices for potatoes. As a result of this and the small size of the farms, migration has become a livelihood strategy, reducing available farm labor. Mountain communities are also experiencing the effects of climate change (Seth et al. 2010). As others have documented, highlands are among the most vulnerable regions in the world, often the first to experience the effects of climate change(Lobell et al. 2008). The warming and the loss of humidity effects can be buffered by manure as an organic amendment. Used by both vulnerable and better-off households, this practice contributes to the adaptive capacity of these farming systems.

In all cases the variable for place and context was significant. Location does make a difference. Residents in the poorer communities of the northern Altiplano were more likely to use manure, while those of the more prosperous central Altiplano communities were more likely to use bioindicators and conserve more potato varieties (Valdivia et al. 2010). However, this result also does not support the diffusion-of-innovation findings because two of the three traditional practices are maintained in the wealthier municipio. Education was related to the loss of traditional practices only in the case of bioindicators. In other practices education was not significant. Traditional explanations of why bioindicators work have invoked Andean cosmology. For this reason, some evangelical Christians and some secular people have abandoned these practices because of their association with "pagan" beliefs. Both these groups have higher educational levels than their neighbors.

A constraint to the use of traditional techniques appears to be the availability of tractors in the cases of manure and crop biodiversity. 
Tractors are a labor-saving device well suited to applying chemical fertilizer, but ill suited for the traditional application method of applying manure around each potato seeded. When a tractor is used, manure must be applied separately from seeding, which requires more labor. Access to tractors is also limited as there are only a few in each community so farmers must rent them and wait in line to use them behind the owners. The decision on planting time depends on when the tractor is available (Valdivia et al. 2003). The topography and plot size also limit the use of tractors.

Current livelihood strategies for many farmers involve educating children for nonfarm careers and seeking off-farm employment or using off-farm enterprises to supplement income. Both strategies reduce the amount of labor available for monitoring bioindicators and have affected the ability of farmers to choose planting times. In areas that are flat enough to permit the use of tractors, mechanization is one strategy used, but mechanized land preparation is more conducive to the use of chemical fertilizers that can be incorporated into the soil at planting time.

Producers who have the highest incomes were more likely to use manure together with commercial fertilizers, while the poor used manure alone. High-income farmers also were more likely to grow a larger number of potato varieties. This finding echoes that of Moore (2008), who found that local knowledge systems typically included modern and traditional practices. Labor saving is one factor that has led to the adoption of the Waycha potato variety as harvesting this variety is less labor-intensive than other varieties because its tubers are more concentrated around the base of the plant.

Low incomes and lack of education are not strongly associated with the use of traditional farming practices. Low income is only related to manure use, and even then the square of income is significant, indicating that the richest farmers also use manure. Education is not associated with the use of manure or conservation of potato varieties. There is a negative relationship between primary and secondary education and use of bioindicators, but there is no relationship between postsecondary education and use of these indicators. Finally, high-income families raise more varieties of potatoes, and the highest-income families are more likely to use manure, having the resources to invest in this practice.

It appears that one of the reasons for the losses of traditional practices is a breakdown in the transmission of traditional knowledge. Traditional knowledge, as a form of local knowledge, is transmitted informally as family members spend time together in the fields rather than in formal teaching situations. The fact that young people are going to school and 
then have off-farm employment mostly limits their participation in agriculture to planting and harvesting. So even though youth are aware that their elders have this knowledge, they no longer have an opportunity to learn it. This suggests a role for extension and community development organizations who can provide venues where this knowledge can be transmitted.

Isolation and poverty do not seem to be associated with conservation of traditional technologies. We found no significant relationship between conservation of traditional practices and distances to market. Remoteness to market was reported as time to travel to market.

In use of bioindicators and maintenance of potato biodiversity, the more prosperous, market-oriented municipios (Umala) were more likely to conserve traditional practices. In use of manure, the poorer communities were more likely to maintain the practice, but in the communities where this practice was less common, the larger and more educated producers used both manure and chemical fertilizers. In the poorer communities, smaller plots made it easier and less expensive to meet fertilizer needs from their own herds.

The way families integrate into markets seems to be important in determining the use of sustainable practices. Families who have limited labor available for farming because of wage labor of family members have more difficulty maintaining traditional practices than those who focus more on commercial agricultural production. Richer families who do not have difficulty obtaining inputs and scheduling tractor time have maintained traditional practices as have the poor in the case of manure.

It is the large group of farmers in the middle who are less likely to use these practices. This is largely because they lack access to the financial resources needed to pay for seeds, fertilizers, tractor time, and therefore plant when they have the money for seeds, fertilizer, and tractor time, rather than based on indicators. Labor shortages due to larger land areas prevent them from using manure. Improved extension and access to credit might lead to a renewed use of traditional practices.

The three agricultural practices studied here reduce the vulnerability of farmers to climate change. Manure retains soil moisture and buffers soil temperature (Thiebault et al. 2010). Biodiversity, a natural capital, contributes to resilience by reducing risk and increasing opportunities, and bioindicators directly address the issue of climate risk. However, all these techniques demand a significant amount of time. Farmers who have more labor, assets, and land find it easier to "afford" the maintenance of traditional practices. For example, applying manure requires access to more labor and the ownership of livestock-particularly sheep. Similarly, the use of bioindicators requires that a farmer spend 
considerable time in the field to observe them and that farmers have the flexibility to change production strategies in response to their predictions. This is difficult for those who work off farm. In addition, available tractor-drawn machinery cannot handle manure and makes it difficult to plant multiple crops in the same plot.

In certain situations, the conservation of traditional practices can be viewed as an innovation. That is to say, when practices are all but abandoned some innovators recognize their value and work to conserve them. Veteto (2008) gives an example from North Carolina where the preservers of heirloom seed include both the old and isolated and the young and educated. The latter adopt because they view it as a "new and improved" practice. We might expect that the results of this study might be such a scenario.

However, this is not the case. These practices were not abandoned ones that are being rediscovered. Workshops in each community did not reveal a revival of these practices-in fact many were concerned about their loss. Survey data show that there are still significant numbers of people who use these techniques. In workshops, farmers agreed that the use of these techniques is in decline. In addition, survey data for some communities in Umala from 1994 and 2001 indicate that there has been a decline in these practices over time (Coppock and Valdivia 2001; Gilles and Valdivia 2009). This may change, however, as beginning in 2006 the Bolivian government began promoting the use and conservation of indigenous knowledge.

The three practices examined here increase the resiliency of production systems to cope with climate risk. Adaptation to climate change requires increased resiliency rather than less (Folke et al. 2002). Climate patterns and the high elevation of the Andes underscore the importance of these practices (Lobell et al. 2008). Models predict that weather patterns will become more variable with a later onset of rains and a higher frequency of extreme weather events (Seth et al. 2010). Losing these three practices can undermine people's survival by increasing the vulnerability of their farming systems. Adaptation to climate change requires the adoption of practices like those described here. So the abandonment of them increases the vulnerability of smallholders in the region.

\section{Conclusion}

The findings here put into question some of the assumptions held by the advocates of the revival of traditional, more sustainable farming practices. On the one hand, the fact that these practices are not utilized only 
by the poorest and most marginalized farmers suggests that the task of conserving traditional knowledge may be easier than previously thought. Many of those who preserve this knowledge are successfully adjusting to the market economy and share characteristics of those farmers who adopt modern, Western agricultural practices.

Many communities still have opinion leaders available to advise their neighbors on the use of traditional sustainable practices. If encouraged to do so, these farmers have the resources needed to conserve their heritage. On the other hand, if these results hold for other parts of the world, the conservation of traditional practices might not be of great value to the poorest producers as previously thought. For the poorer producers, global changes such as population increase and market integration have resulted in decreased plot sizes, and increasing difficulties in generating income solely from agriculture. Off-farm employment competes for time with more labor-intensive practices like manure use and planting many varieties and prevents poorer farmers from spending time in the field observing bioindicators. Climate change and declining farm sizes have pushed many farmers to temporarily migrate and their labor is not available on the farm.

The findings also suggest that we reexamine some assumptions that we make about preservation of agricultural practices in the north and the south. First, we must avoid the temptation to view modern and traditional practices as mutually exclusive. More prosperous farmers have the time and resources to devote to preservation that their poorer neighbors may not. In the Bolivian case we see larger farmers planting multiple commercial and traditional potato varieties, the former to reduce risk and the latter because these varieties are preferred for specific meals and have ritual value (Materer 2001).

Labor availability especially in the case of low-income farmers is a crucial factor in determining the use of traditional practices in Bolivia and may also be the case in the United States. While available time may be critical for the adoption of sustainable practices, incentives that place value on adopting them may be able to overcome this constraint. In the context of designing policies to facilitate adaptation to climate change, this is a key opportunity to develop favorable incentive mechanisms.

This study highlights the need to understand the mechanisms that lead to the abandonment of sustainable practices instead of studying the adoption process. It also shows that the preservation of valuable agricultural practices may require investment by governments or development agencies in mechanisms that replace traditional ways of transmitting knowledge-especially in ways that strengthen and create farmer-tofarmer networks of communication. 


\section{References}

Aguirre, G. J. C., D. Buitrago, V. Iriarte, J. Ramos, J. Blajos, G. Thiele, and A. Devaux. 1999. Rustic Seedbeds: A Bridge between Formal and Traditional Potato Seed Systems in Bolivia. Lima, Peru: International Potato Center.

Altieri, Miguel A. 1999. "Applying Agroecology to Enhance the Productivity of Peasant Farming Systems in Latin America." Environment, Development and Sustainability $1(3): 197-217$.

—. 2004. "Linking Ecologists and Traditional Farmers in the Search for Sustainable Agriculture." Frontiers in Ecology and the Environment 2(1):35-42.

Bellón, Mauricio R. 2004. "Conceptualizing Interventions to Support On-Farm Genetic Resource Conservation.” World Development 32(1):159-72.

Bennett, Elena M. and Patricia Balvanera. 2007. "The Future of Production Systems in a Globalized World." Frontiers in Ecology and the Environment 5:191-98.

Brush, Steven B. 2004. Farmers'Bounty: Locating Crop Diversity in the Contemporary World. New Haven, CT: Yale University Press.

Brush, Steven B., J. Edward Taylor, and Mauricio R. Bellón. 1992. "Technological Adoption and Biological Diversity in Andean Potato Agriculture." Journal of Development Economics 39(2):365-87.

Chambers, Robert, Arnold Pacey, and Lori Ann Thrupp. 1989. Farmer First: Farmer Innovation and Agricultural Research. New York: Bootstrap Press.

Constance, Douglas H. 2009. "2008 AFHVS Presidential Address." Agriculture and Human Values 26(1-2):3.

Coppock, D. Layne and Corinne Valdivia, eds. 2001. Sustaining Agropastoralism in the Bolivian Altiplano: The Case of San Jose Llanga. Logan, UT: Department of Rangeland Sciences, Utah State University.

Fernandes, Erick C. M., Peter Motavalli, Carlos Castilla, and Linus Mukurumbira. 1997. "Management Control of Soil Organic Matter Dynamics in Tropical Land-use Systems." Geoderma 79:49-67.

Folke, C., S. Carpenter, T. Elmqvist, L. Gunderson, C. S. Holling, and B. Walker. 2002. "Resilience and Sustainable Development: Building Adaptive Capacity in a World of Transformations." Ambio 31(5):437-40.

García, Magali, D. Raes, S. E. Jacobsen, and T. Michel. 2007. "Agroclimatic Constraints for Rainfed Agriculture in the Bolivian Altiplano." Journal of Arid Environments 71 (1):109_ 21.

Garrett, Karen A. 2000. "Factors Influencing the Effects of Host Diversity on Plant Disease Epidemics for Wheat Stripe Rust and Potato Late Blight.” PhD dissertation, Oregon State University, Corvallis, OR.

Giller, Ken E., Ernst Witter, Marc Corbeels, and Pablo Tittonell. 2009. "Conservation Agriculture and Smallholder Farming in Africa: The Heretics' View." Field Crops Research 114(1):23-34.

Gilles, Jere L. and Corinne Valdivia. 2009. "Local Forecast Communication in the Altiplano." Bulletin of the American Meteorological Society 90(1):85-91.

Grabowski, Richard. 1979. "The Implications of an Induced Innovation Model." Economic Development and Cultural Change 27:723-34.

Griliches, Zvi. 1957. "Hybrid Corn: An Exploration in the Economics of Technological Change." Econometrica 25(4):501-22.

- 1960. "Hybrid Corn and the Economics of Innovation." Science 132(3422):275-80.

Gurung, Barun and Harriet Menter. 2004. "Mainstreaming Gender-Sensitive Participatory Approaches: The CIAT Case Study.” Pp. 257-85 in Scaling Up and Out: Achieving Widespread Impact through Agricultural Research, edited by D. Pachico and S. Fujisaka. Cali, Colombia: CIAT.

Hawkes, Jack G. and J. Peter Hjerting. 1989. The Potatoes of Bolivia: Their Breeding Value and Evolutionary Relationships. Oxford, England: Oxford University Press.

Hayami, Yujiro. 1981. "Induced Innovation, Green Revolution, and Income Distribution: Comment." Economic Development and Cultural Change 30(1):169-76. 
Hayward, Chris, Lyn Simpson, and Leanne Wood. 2004. "Still Left Out in the Cold: Problematizing Participatory Research and Development." Sociologia Ruralis 44(1):95108.

Knowler, Duncan and Ben Bradshaw. 2007. "Farmers' Adoption of Conservation Agriculture: A Review and Synthesis of Recent Research.” Food Policy 32(1):2548.

Lobell, D. B, M. B. Burke, C. Tebaldi, M. D. Mastrandrea, W. P. Falcon, and R.L. Naylor. 2008. "Prioritizing Climate Adaptation Change: Adaptations for Food Security in 2030." Science 319:607-10.

Long, J. Scott. 1997. Regression Models for Categorical and Limited Dependent Variables. Bloomington, IN: Sage Publications.

Markowitz, Lisa and Corinne Valdivia. 2001. "Patterns of Technology Adoption at San José Llanga: Lessons in Agricultural Change." Pp. 239-56 in Sustaining Agropastoralism on the Bolivian Altiplano: The Case of San Jose Llanga, edited by D. L. Coppock and C. Valdivia. Logan, UT: Rangeland Resources Department, Utah State University.

Materer, Susan M. 2001. "The Role of Potato Production in Diversified Economic Household Portfolios: Study of San Jose Llanga.” MA thesis, Department of Agricultural Economics, University of Missouri, Columbia, MO.

Moore, Keith M. 2008. "Network Framing of Pest Management Knowledge and Practice." Rural Sociology 73(3):414-39.

Nazarea, Virginia D. 2005. Heirloom Seeds and Their Keepers: Marginality and Memory in the Preservation of Biodiversity. Tuscon, AZ: University of Arizona Press.

Orlove, Benjamin S., John C. H. Chiang, and Mark A. Cane. 2000. "Forecasting Andean Rainfall and Crop Yield from the Influence of El Niño on Pleiades Visibility." Nature 403:68-71.

- 2002. "Ethnoclimatology in the Andes: A Cross-disciplinary Study Uncovers a Scientific Basis for the Scheme Andean Potato Farmers Traditionally Use to Predict the Coming Rains." American Scientist 90(5):428-35.

Rogers, Everett M. 2003. Diffusion of Innovations. 5th ed. New York: Free Press.

Ryan, Bruce G. and Neal C. Gross. 1943. "The Diffusion of Hybrid Seed Corn in Two Iowa Communities." Rural Sociology 8(1):15-24.

Saltiel, John, James W. Bauder, and Sandy Palakovich. 1994. "Adoption of Sustainable Agricultural Practices: Diffusion, Farm Structure, and Profitability.” Rural Sociology $59(2): 333-49$.

Schlebecker, John T. 1977. "Farmers and Bureaucrats: Reflections on Technological Innovation in Agriculture." Agricultural History 51(4):641-55.

Seth, Anji, Jeanne Thibeault, Magali García, and Corinne Valdivia. 2010. "Making Sense of Twenty-First-Century Climate Change in the Altiplano: Observed Trends and CMIP3 Projections." Annals of the Association of American Geographers 100(4):83547.

Shively, Gerald E. 1997. "Consumption Risk, Farm Characteristics, and Soil Conservation Adoption among Low-Income Farmers in the Philippines." Agricultural Economics 17:165-77.

Sillitoe, Paul. 1998. "The Development of Indigenous Knowledge: A New Applied Anthropology." Current Anthropology 39(2):223-52.

Sillitoe, Paul and Mariella Marzano. 2009. "Future of Indigenous Knowledge Research in Development." Futures 41(1):13-23.

Tabachnick, Barbara G. and Linda S. Findell. 2007. Using Multivariate Statisitcs. 5th ed. Boston, MA: Pearson Education.

Thibeault, Jeanne, Anji Seth, and G. Wang. 2010. "Mechanisms of Summertime Precipitation Variability in the Bolivian Altiplano: Present and Future" International Journal of Climatology 32(12):2033-41. doi:10.1002/joc.2424.

Valdivia, Corinne. 2004. "Andean Livelihood Strategies and the Livestock Portfolio." Culture and Agriculture 26(1-2):69-79. 
Valdivia, Corinne, Elizabeth G. Dunn, and Christian Jetté. 1996. "Diversification as a Risk Management Strategy in an Andean Agropastoral Community." American Journal of Agricultural Economics 78(5):1329-34.

Valdivia, Corinne, Jere L. Gilles, Christian Jetté, Roberto Quiroz, and Rigoberto Espejo. 2003. "Coping and Adapting to Climate Variability: The Role of Assets, Networks, Knowledge and Institutions." Pp. 189-99 in Insights and Tools for Adaptation: Learning from Climate Variability. Washington, DC: National Oceanic and Atmospheric Administration Office of Global Programs, Climate and Societal Interactions.

Valdivia, Corinne, Anji Seth, Jere L. Gilles, Magali García, Elizabeth Jiménez, Jorge Cusicanqui, Fredy Navia, and Edwin Yucra. 2010. "Adapting to Climate Change in Andean Ecosystems: Landscapes, Capitals, and Perceptions Shaping Rural Livelihood Strategies and Linking Knowledge Systems." Annals of the Association of American Geographers $100(4): 818-34$.

Veteto, James. 2008. "The History and Survival of Traditional Heirloom Vegetable Varieties in the Southern Appalachian Mountains of Western North Carolina." Agriculture and Human Values 25(1):121-34.

Warren, Dennis M. 1991. Using Indigenous Knowledge in Agricultural Development. Washington, DC: World Bank.

Wejnert, Barbara. 2002. "Integrating Models of Diffusion of Innovations: A Conceptual Framework." Annual Review of Sociology 28:297-326.

Zimmerer, Karl S. 1993. "Soil Erosion and Labor Shortages in the Andes with Special Reference to Bolivia, 1953-91: Implications for Conservation-With-Development." World Development 21(10):1659-75. 